\title{
Studi Awal Penggunaan Metode JIGSAW Dalam Peningkatan Pemahaman Personil Institusi Pengujian dan Kalibrasi Alat Kesehatan Terhadap SNI 17025:2017
}

\author{
Yeni Pertiwi $^{1}$, Kamal Mahmudi ${ }^{2}$, Rino Ferdian Surakusumah ${ }^{3}$, Nur Hadziqoh ${ }^{4}$, Icha Fatwasauri ${ }^{5}$ \\ Jurnal Kalibrasi \\ Program Studi Rekayasa Elektro-medis \\ Sekolah Tinggi Ilmu Kesehatan Al-Insyirah Pekanbaru \\ Jl. Parit Indah No.38 Kota Pekanbaru, Provinsi Riau \\ Email : psik@stikes-alinsyirah.ac.id \\ 1yenipertiwi16@gmail.com \\ ${ }^{2}$ kamalmahmudi@gmail.com \\ ${ }^{3}$ rino.stalinsyirah@gmail.com \\ ${ }^{4}$ nurhadziqoh@gmail.com \\ 5ichafatwasauri@gmail.com
}

\begin{abstract}
Abstrak - Penjaminan mutu merupakan hal terpenting dalam pengujian dan atau kalibrasi, khususnya pada berbagai alat kesehatan. Semua lembaga pengujian dan atau kalibrasi alat kesehatan harus memiliki referensi yang sama agar hasilnya dapat dipertanggungjawabkan. Acuan yang digunakan di Indonesia untuk menjamin sistem manajemen mutu laboratorium adalah SNI ISO 17025: 2017. Oleh karena itu, setiap personil yang bekerja di laboratorium harus memahami dan menerapkan persyaratan yang diatur pada SNI tersebut. PT. XYZ merupakan lembaga pengujian dan atau kalibrasi alat kesehatan yang baru beroperasi dan akan mengadopsi sistem SNI ISO 17025 sebagai kebijakan perusahaan untuk meningkatkan kualitas hasil laboratoriumnya. Semua Personel PT. XYZ pernah mendapatkan sosialisasi tentang persyaratan standar tersebut yang dilakukan oleh manajer mutu dengan menggunakan metode ceramah, namun terdapat beberapa keluhan dari beberapa personel yang tidak memahami standar tersebut. Sehingga penelitian ini bertujuan meningkatkan pemahaman personel PT XYZ terhadap persyaratan SNI ISO 17025: 2017 dengan menerapkan metode pembelajaran kooperatif JIGSAW. Penilaian peningkatan pemahaman personeldilakukan dengan analisis uji-t dan uji skala likert. Hasil studi awal menunjukkan bahwa penerapan metode JIGSAW dalam meningkatkan pemahaman personil memberikan perbedaan yang signifikan terhadap peningkatan personel. Peningkatan pemahaman personel setelah pelatihan dengan metode ini meningkat sebesar $35 \%$. Uji skala likert juga menunjukkan bahwa penilaian peserta pelatihan terhadap pelatih berada pada kategori Baik dan penilaian peserta terhadap pelaksanaan kegiatan sangat sesuai sehingga dapat disimpulkan bahwa pelatihan interpretasi pemahaman personel SNI ISO 17025: 2017 menggunakan metode JIGSAW efektif.
\end{abstract}

Kata Kunci - ISO 17025; Laboratorium Kalibrasi; JIGSAW; Pelatihan.

\section{PENDAHULUAN}

Sistem manajemen mutu laboratorium adalah suatu sistem yang dipakai untuk mencapai sasaran dan tujuan yang telah ditetapkan. Agar tercapainya sasaran dan tujuan, laboratorium harus menjalankan praktik laboratorium dengan baik dan benar. Penerapan GLP (Good Laboratory Practices) dalam proses kegiatan laboratorium dapat meningkatkan kepercayaan dan kepuasan pelanggan. GLP merupakan alat manajemen 
dalam praktik laboratorium untuk menghasilkan mutu data pengujian yang konsisten, mencegah ketidaksesuaian serta peningkatan mutu [1]. Untuk mencapai GLP laboratorium harus menerapkan sistem manajemen mutu yang efektif dengan perbaikan terus menerus. Laboratorium harus mampu mengukur dan mengontrol manajemen mutunya, agar upaya perbaikan terus menerus dapat diterapkan. Untuk itu, perlu adanya suatu standar yang mampu mengukur dan mengontrol kegiatan laboratorium. Adapun standar yang umum digunakan oleh laboratorium atau suatu institusi adalah International Standard Organisation (ISO).

Dalam praktiknya laboratorium uji kalibrasi di Indonesia menggunakan standar acuan SNI ISO 17025. Penggunaan standar ISO ini sudah di mulai dari tahun 1978 sampai sekarang. Pada tahun 2017, ISO 17025 sudah ditinjau dan relevan dengan perkembangan industri saat ini.ISO 17025 ini merupakan standar yang mengatur persyaratan umum kompetensi laboratorium pengujian dan atau laboratorium kalibrasi. Untuk dapat menunjukkan kemampuan laboratorium dalam memberikan hasil yang terpercaya makainstitusi uji kalibrasi harus melaksanakan penjaminan mutu dan keabsahan hasil.

Penjaminan mutu dan keabsahan hasil merupakan hal yang paling utama dalam melakukan uji kalibrasi terutama pada alat kesehatan. Seluruh institusi uji kalibrasi alat kesehatan harus memiliki acuan yang sama sehingga hasilnya dapat dipertanggungjawabkan. Hal ini dapat terjamin dengan adanya standar dan regulasi baik dalam lingkup nasional maupun internasional.

Di Indonesia, persyaratan institusi uji kalibrasi fasilitas kesehatan diatur dalam Peraturan Menteri Kesehatan No.54 Tahun 2015 tentang uji kalibrasi alat kesehatan [2]. Tata cara pengajuan izin operasionalnya diatur lebih lanjut pada Permenkes No. 262018 tentang Pelayanan Perizinan Berusaha Terintegrasi Secara Elektronik Sektor Kesehatan [3]. Peraturan ini mencakup persyaratan sumber daya manusia, sarana prasarana, dan dokumen penjaminan mutu internal.

Standar berikutnya yang wajib menjadi rujukan seluruh institusi pengujian fasilitas kesehatan di Indonesia adalah metode kerja uji kalibrasi alat kesehatan yang telah dirancang oleh kementerian kesehatan dalam Keputusan Direktur Jenderal Pelayanan Kesehatan Nomor: HK.02.02/V/5771/2018. Metode kerja ini mencakup prosedur operasional distribusi dan pengendalian dokumen, prosedur operasional pernyataan kesesuaian dan aturan keputusan, metode kerja uji keselamatan listrik, metode kerja perhitungan ketidakpastian pengukuran secara umum, dan metode kerja spesifik untuk 68 jenis alat kesehatan [4].

Laboratorium uji kalibrasi dalam SNI ISO 17025:2017 memiliki persyaratan umum kompetensi yang mengatur tentang syarat ketidakberpihakan dan kerahasian, struktur organisasi, sumber daya manusia, sarana prasarana dan kondisi lingkungan, peralatan yang dimiliki, ketertelusuran, pemilihan, verifikasi dan validasi metode uji kalibrasi, proses kaji ulang permintaan, tender, dan kontrak, pengelolaan barang yang diuji kalibrasi, dan persyaratan manajemen [5].

PT. XYZ merupakan institusi yang bergerak dibidang uji kalibrasi alat kesehatan. PT. XYZ akan menerapkan sistem ISO 17025 sebagai komitmen institusi untuk menjaga kualitas hasil laboratoriumnya. Personil PT. XYZ telah mendapatkan pelatihan tentang pengenalan kebijakan ISO SNI 17025:2017 tetapi belum pernah dilakukan pelatihan dan penilaian pemahaman terhadap persyaratan yang ada padastandar ISO tersebut. Salah satu upaya peningkatan pemahaman SNI ISO 17025 kepada personil PT. XYZ dengan memberikan pelatihan. Hal ini bertujuan agar semua personel dapat menerapkan sistem GLP dalam menjalankan kegiatan laboratorium.

Kegiatan pelatihan pada umumnya memakai metode ceramah dan diskusi. Selain itu [6] dalam penelitiannya di perusahaan PT. Beon Intermedia juga menyebutkan metode pelatihan yang sering diterapkan adalah seminar dalam bentuk ceramah dan dinilai kurang efisien dalam meningkatkan kemampuan peserta. Selanjutnya, Tambak [7] menyatakan penerapan metode ceramah membuat peserta kurang kreatif dan cenderung bersikap pasif dalam kegiatan sehingga guru/pelatih sulit mengetahui sampai dimana tingkat pemahaman peserta, dan juga hal ini akan menimbulkan beberapa salah tafsir materi pelatihan oleh peserta. Dalam Maurin [8], Lestari [9], Ranabumi [10] juga menyatakan bahwa untuk meningkatkan motivasi dan pemahaman dalam proses pembelajaran tidak cukup hanya memakai metode ceramah saja. Dari permasalahan diatas perlu ditemukan 
metode yang tepat dalam meningkatkan pemahaman personel PT. XYZ terhadap ISO/IEC 17025: 2017. Salah satu teknik pembelajaran dalam pelatihan adalah dengan menerapkan metode pembelajaran kooperatif JIGSAW. Ketut menyatakan bahwa dengan menerapkan secara efektif metode jigsaw sebagai model pembelajaran dapat meningkatkan sikap demokrasi peserta pendidikan dan pelatihan yang dilaksanakan di Provinsi Bali [11]. Menurut Majid, metode JIGSAW merupakan model pembelajaran kooperatif dengan membentuk kelompok dengan anggota yang heterogen yang terdiri dari empat sampai dengan enam orang dan setiap anggota saling bekerjasama dan dan saling bertanggung jawab secara mandiri. Ifa mengatakan bahwa dengan mengaplikasikan metodeJIGSAW terjadi peningkatan hasil belajar sebesar 10,72\% [12]. Kusuma dalam penelitiannya juga menyatakan penerapan metode ini dapat meningkatkan hasil belajar siswa sebesar $32,14 \%$ [13]. Dari paparan yang sudah disampaikanmaka penelitian ini bertujuan untuk menganalisis penggunaan metode JIGSAW dalam meningkatkan pemahaman personil PT. XYZ terhadap persyaratan SNI ISO/IEC 17025:2017.

Berdasarkan uraian diatas, dalam meningkatkan kualitas institusi uji kalibrasi PT. XYZ maka diperlukan suatu pelatihan dalam meningkatkan pemahaman personilnya terhadap penerapan SNI ISO 17025:2017 sehingga penelitian ini bertujuan untuk untuk meningkatkan pemahamanpersonil PT. XYZ terhadap persyaratan SNI ISO 17025:2017 dengan menggunakan model pembelajaran kooperatif metode JIGSAW.

\section{URAIAN PENELITIAN}

Penelitian ini menggunakan penelitian jenis pendekatan kuantitatif karena semua data yang diambil berupa angka dan hasilnya diolah dengan analisis statistik. Metode JIGSAW didefinisikan sebagai proses pembelajaran berkelompok yang berpengaruh positif dalam membuat berbagai bentuk suasana pola diskusi. Dalam proses diskusi dibutuhkan pengorganisasian untuk mengendalikan kelompok secara keseluruhan, dan bentuk kegiatan dirancang untuk membuat setiap anggota kelompoklebih banyak berfikir untuk mengembangkan pengetahuannya baik secara pribadi anggota maupun dengan saling membantu sesama anggota kelompok.

Selain itu, metode ini dapat melatih sikap mau menerima saran, dan kritik serta sikap bertanggung jawab. Metode jigsaw adalah bentuk pembelajaran kooperatif dengan membentuk kelompok kecil yang terdiri dari 46 anggota secara heterogen. Setiap kelompok mendapatkan beberapa topik dan setiap anggota kelompok bertanggung jawab atas penyelesaian bagian topik yang harus dipelajari. Setelah melakukan pelatihan hasil uji metode dan kepuasan peserta akan di uji menggunakan pengujian Paired Sample T-Test dan pengujian Skala Likert.

Pengujian Paired SampleT-Test adalah metode pengujian yang digunakan untuk mengetahui pengaruh penggunaan metode pada suatu sampel. Objek penelitian pada pengujian paired sample T-Test ini mendapatkan tindakan yang berbeda, misalnya sebelum diberikan pelatihan, kemampuan personel akan dites dulu. Setelah perlakuanditerapkan personel di tes kembali dengan melaksanakan posttest. Jadi analisis pengujian paired sample T-test ini mempunyai dua data dengan individu yang sama.

Skala Likert merupakan teknik dalam pemberian skor yang digunakan dalam angket yang diberikan kepada peserta untuk mengetahui skala sikap suatu objek tertentu. Menurut Sugiyono yang tertuang di dalam bukunyatentang Metode Penelitian Kuantitatif, Kualitatif dan R\&D, tahun 2012 hal pertama yang harus dilakukan adalah penentuan skala dan nilai dari setiap jawaban yang akan diberikan. hal ini bertujuan agar narasumber dapat memberikan penilaian sesuai dengan kriteria mereka berdasarkan pilihan yang ada. Perhitungan nilai ideal menggunakan persamaan:

skala kriterium $=$ Nilai skala $x$ Jumlah narasumber 
Selanjutnya semua hasil respon dari narasumber dijumlahkan dan dimasukkan ke dalam rating scale dan ditentukan jawabannya. rating scale ini bertujuan untuk mengetahui hasil data angket secara keseluruhan yang didapat dari penilaian angket. Terakhir menentukan jumlah jawaban dan para narasumber melalui persentase dengan persamaan:

$$
\text { Persentase }=\frac{\text { Frekuensi Jawaban kuesioner }}{\text { Jumlah Skor Ideal }} 100 \%
$$

Adapun tahap tahap penerapan metode jigsaw yang dipersiapkan dalam pelatihan ini sebagai berikut:

1. Pembuatan Soal Pretest dan Posttest

Pembuatan soal pretest diambil dari 8 klausul yang ada pada SNI ISO 17025:2017 berjumlah 20 soal pilihan ganda. Kemudian untuk soal postest dipakai soal yang sama dengan soal pretest namun dilakukan pengacakan pada soal postestnya.

2. Pretest

Pretest diberikan sebelum dilakukan diskusi kelompok menggunakan metode jigsaw untuk mengetahui tingkat pemahaman peserta terhadap SNI SNI ISO/17025:2017

3. Diskusi Kelompok

Jumlah peserta dalam penelitian ini sebanyak 7 peserta dan dibagi kedalam 2 kelompok. Kelompok asal masing-masing diberikan tiga topik dan membuat kesimpulan di setiap topik.

4. Membagi peserta ke dalam kelompok ahli

Dari kelompok asal dibentuklah kelompok ahli yang bertugas menjelaskan topik yang didapat dari kelompok asal kepada kelompok ahli.

5. Laporan tim

Setelah dari kelompok ahli, para peserta kembali ke kelompok asal untuk menyampaikan kesimpulan yang didapat

6. Posttest

Setelah semua anggota kelompok paham, akan diberikan soal posttest. Soal posttest berguna untuk melihat peningkatan kemampuan peserta setelah berdiskusi kelompok menggunakan metode jigsaw. Adapun ilustrasi pembagian kelompok ini dapat dilihat pada Gambar 1.

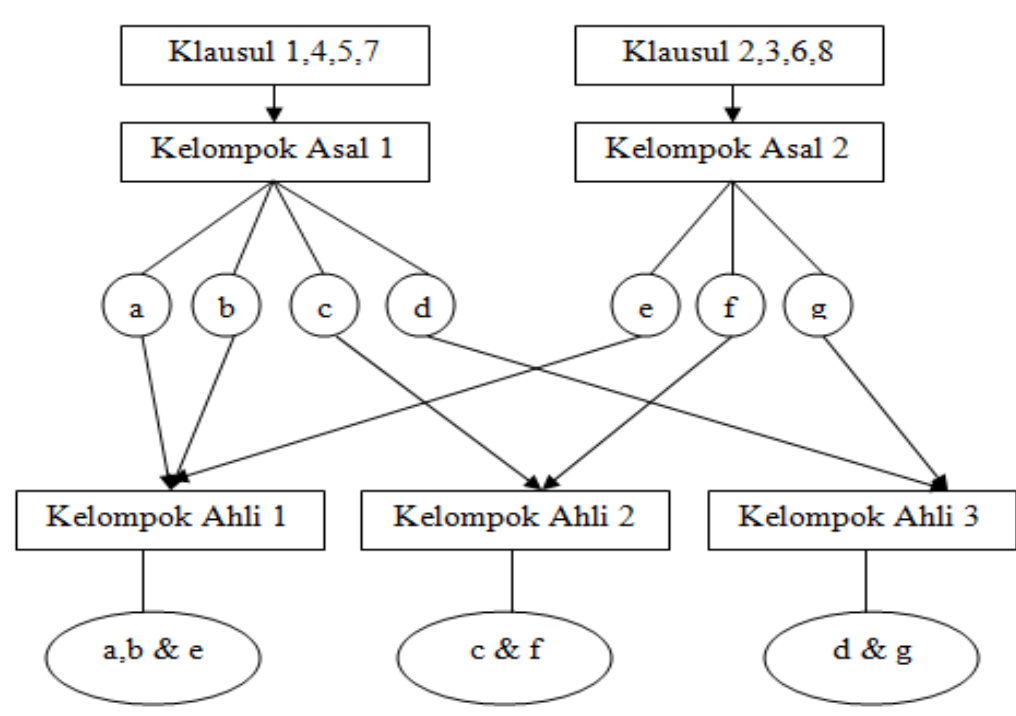

Gambar 1: Peta Pembagian kelompok dan pembagian topik diskusi

Hasil pretest dan posttest personil setelah dilakukan pelatihan diuji dengan menggunakan metode Uji Paired sample T-Test untuk mengetahui pengaruh signifikan variabel dependen dan variabel independen secara parsial. Perhitungan dilakukan dengan menggunakan Microsoft Excel. Adapun hipotesis pada penelitian ini adalah: 


$$
\begin{aligned}
& H_{0}: \mu_{1}-\mu_{2}=0 \\
& H_{1}: \mu_{1}-\mu_{2} \neq 0
\end{aligned}
$$

$\mathrm{H}_{0}=0$ : Selisih Nilai Rata-rata Posstest dan Pretest

$\mathrm{H}_{1} \neq 0$ : Selisih Nilai Rata-rata Posstest dan Pretest

H0 dan H1 ditentukan dari nilai probabilitas $\left(P_{\text {value }}\right)$ dan ( $\left.t_{\text {hitung }}\right)$. Nilai $P_{\text {value }}$ merupakan nilaikesalahan yang di dapat dari hasil perhitungan statistik. Nilai thitungdigunakan untuk mengetahui kualitas keberartian regresi antara tiap-tiap variabel independen terdapat pengaruh atau tidak terhadap variabel dependen. Nilai thitung diperoleh dari analisis software Microsoft Excel. Sedangkan nilai t-tabel di ambil dari Tabel T Statistik. Apabila $t_{\text {hitung }}>t_{\text {tabel }}$ berbeda maka $H_{0}$ ditolak begitu juga sebaliknya. Jika nilai $\mathrm{p}$ value $\leq \boldsymbol{\alpha}$ maka $\mathrm{H}_{0}$ ditolak dan $\mathrm{H}_{1}$ diterima.

Untuk mengukur penilaian peserta terhadap penyelenggaraan kegiatan dan pelatih diberikan kuesioner kepada peserta sebanyak 4 pertanyaan yang berkaitan dengan penyelenggaran kegiatan dan 9 pertanyaan yang berkaitan tentang trainer. Skala dan skor yang diberikan ditunjukkan pada tabel 1 dan 2.

Tabel 1: Skor Penyelenggaraan Kegiatan

\begin{tabular}{lcc}
\hline \multicolumn{1}{c}{ Jawaban } & Skor & Skala \\
\hline Tidak Sesuai & 1 & $0-7$ \\
\hline Kurang Sesuai & 2 & $8-14$ \\
\hline Sesuai & 3 & $15-21$ \\
\hline Sangat Sesuai & 4 & $22-28$ \\
\hline
\end{tabular}

Tabel 2: Skor Penilaian Pelatih

\begin{tabular}{lcc}
\hline \multicolumn{1}{c}{ Jawaban } & Skor & Skala \\
\hline Kurang & 1 & $0-7$ \\
\hline Cukup & 2 & $8-14$ \\
\hline Baik & 3 & $15-21$ \\
\hline Baik Sekali & 4 & $22-28$ \\
\hline
\end{tabular}

Untuk penetapan skala digunakan metode skala likert dimana nilai tertinggi diambil dari perkalian nilai 4 dengan jumlah responden 7 yaitu 28. Sedangkan nilai terendah diambil dari perkalian nilai 1 dengan jumlah responden 7. Jadi jika perolehan skor total antara 0-7 maka kesimpulannya Kurang/Tidak Sesuai. Karena Jumlah responden 7 orang maka intervalnya penilaian dibuat 7. Jadi skala 8-14 masuk pada kriteria Cukup/Kurang Sesuai. Kriteria Baik/Sesuai berada pada interval 15-21 selanjutnya kriteria Baik Sekali / Sangat Sesuai berada pada interval 22-28.

\section{HASIL DAN PEMBAHASAN}

\section{A. Uji Paired Sample T-Test}

Tabel 3 menunjukkan data hasil pretest dan posttest personil NIQ Teknik Indonesia. Pretest dilakukan sebelum metode JIGSAW diterapkan. Sedangkan posttest dilakukan setelah melakukan pelatihan tentang Persyaratan yang ada pada SNI ISO/IEC 17025:2017 dengan menerapkan metode JIGSAW.

Tabel 3: Nilai Pretest dan Posttest 


\begin{tabular}{ccc}
\hline Peserta & Nilai Pretest & Nilai Posttest \\
\hline 1 & 60 & 77,5 \\
\hline 2 & 67,5 & 82,5 \\
\hline 3 & 47,5 & 57,5 \\
\hline 4 & 45 & 57,5 \\
\hline 5 & 45 & 52,5 \\
\hline 6 & 30 & 60 \\
\hline 7 & 55 & 85 \\
\hline
\end{tabular}

Tabel 4: Hasil Analisis

\begin{tabular}{lrr}
\hline \multicolumn{1}{c}{ Paired Two Sample for Means } & Nilai Pretest & Nilai Posttest \\
\hline Mean & 50 & 67.5 \\
\hline Variance & 147.916667 & 185.41667 \\
\hline Observations & 7 & 7 \\
\hline Df & 6 & \\
\hline Pearson Correlation & 0.75479163 & \\
\hline Hypothesized Mean Difference & 0.00114176 & \\
\hline $\mathrm{P}(\mathrm{T}<=\mathrm{t})$ one-tail & 5.07198186 & \\
\hline $\mathrm{t}$ Stat & 0.00228352 & \\
\hline $\mathrm{P}(\mathrm{T}<=\mathrm{t})$ two-tail & 2.44691185 & \\
\hline $\mathrm{t}$ Critical two-tail & 1.94318027 & \\
\hline $\mathrm{t}$ Critical one-tail & & \\
\hline
\end{tabular}

Jika dilihat dari nilai pretest dan posttest, terdapat peningkatan nilai setelah diterapkan metode JIGSAW . Nilai pretest merupakan nilai pemahaman personel terhadap ISO 17025 setelah dilakukan sosialisasi oleh manajer mutu PT XYZ dengan menggunakan metode ceramah. Sedangkan nilai postest merupakan nilai pemahaman personel setelah dilakukan pelatihan dengan menggunakan metode JIGSAW. Untuk memperkuat analisis terhadap pretest dan posttest, maka dilakukan analisis uji t-test. Uji ini dilakukan untuk mengetahui secara statistik tentang ada atau tidaknya pengaruh penerapan metode JIGSAW terhadap peningkatan pemahaman personil. Hasil uji t-test dapat dilihat pada tabel 4

Pada tabel 4 Terlihat nilai mean (rata-rata) pretest 50 dan nilai rata-rata postestnya 67.5 dari nilai rataratadapat dihitung persentasepeningkatan pemahaman personil terhadap standar SNI ISO/IEC 17025:2017 adalah $35 \%$. Nilai Variance merupakan nilai variasi dari output pretest sebesar 149.92 dan nilai variasi dari output posttest adalah 185.42. Sedangkan nilai t-Stat adalah 5,072 lebih besar dari nilai t Critical one-tail (ttabel nya) 1,943 dan nilai probabilitas nya $\mathrm{P}(\mathrm{T}<=\mathrm{t})$ one-tail atau biasa disebut $\mathrm{p}$-value 0.00114 lebih kecil dari nilai $\boldsymbol{\alpha} 0,05$. Berdasarkan data t-hitung dan $\mathrm{p}$ - value, maka $H_{0}$ ditolak dan $H_{1}$ diterima. Analisis uji t-test menyatakan, penerapan metode JIGSAW dalam pelatihan personil memberikan perbedaan yang nyata. Artinya penerapan metode ini berhasil dalam meningkatkan pemahaman personil PT. XYZ terhadap persyaratan yang ada pada klausul SNI ISO/IEC 17025:2017.

\section{B. Hasil Uji Skala Likert}

Tabel 5: Hasil Penilaian Penyelenggaraan Kegiatan 


\begin{tabular}{|c|c|c|c|c|c|c|c|}
\hline \multirow[b]{2}{*}{ No } & \multirow[b]{2}{*}{ Aspek Penilaian Penyelenggara Pelatihan } & \multicolumn{4}{|c|}{ Nilai } & \multirow[b]{2}{*}{ Skor } & \multirow[b]{2}{*}{ Hasil } \\
\hline & & $\begin{array}{cl}4 \\
S S\end{array}$ & $\begin{array}{ll}3 \\
\end{array}$ & $\begin{array}{c}2 \\
\mathbf{K S}\end{array}$ & 1 & & \\
\hline 1 & $\begin{array}{l}\text { Kesesuaian tema pelatihan dengan yang dibutuhkan } \\
\text { perusahaan }\end{array}$ & 2 & 5 & 0 & 0 & 23 & SS \\
\hline 2 & Ketepatan waktu pelatihan & 1 & 5 & 1 & 0 & 21 & $\mathrm{~S}$ \\
\hline 3 & Pengelolaan waktu saat pelatihan, & 1 & 5 & 1 & 0 & 21 & $\mathrm{~S}$ \\
\hline \multirow[t]{4}{*}{4} & $\begin{array}{l}\text { Adakah improvisasi yang dirasakan terhadap teknik } \\
\text { pelatihan ini }\end{array}$ & 2 & 5 & 0 & 0 & 23 & SS \\
\hline & Jumlah & 6 & 20 & 2 & 0 & 88 & \\
\hline & Jumlah Total & \multicolumn{4}{|c|}{28,0} & 22 & SS \\
\hline & Persentase & 21.4 & $\overline{71.4}$ & 7.1 & 0.0 & & \\
\hline
\end{tabular}

Ket: TS (Tidak Sesuai), SS (Sangat Sesuai), S (Sesuai), KS (Kurang Sesuai)

Tabel 6: Penilaian Pelatih

\begin{tabular}{|c|c|c|c|c|c|c|c|}
\hline \multirow{3}{*}{ No } & \multirow{3}{*}{ Aspek Penilaian Pelatih } & \multicolumn{4}{|c|}{ Nilai } & \multirow{3}{*}{ Skor } & \multirow{3}{*}{ Hasil } \\
\hline & & 4 & 3 & 2 & 1 & & \\
\hline & & BS & B & $\mathbf{C}$ & $\mathbf{K}$ & & \\
\hline 1 & Kelengkapan materi yang disampaikan & 2 & 3 & 2 & 0 & 21 & $\mathrm{~B}$ \\
\hline 2 & Sikap pemateri saat pelatihan & 2 & 4 & 1 & 0 & 22 & BS \\
\hline 3 & Penggunaan media/alat bantu dalam pelatihan & 2 & 3 & 1 & 1 & 20 & $\mathrm{~B}$ \\
\hline 4 & Penilaian terhadap pokok materi yang disampaikan & 2 & 3 & 2 & 0 & 21 & $\mathrm{~B}$ \\
\hline 5 & $\begin{array}{l}\text { Penilaian terhadap pengetahuan dan kemampuan } \\
\text { komunikasi pelatih }\end{array}$ & 2 & 4 & 1 & 0 & 22 & BS \\
\hline 6 & Metode pelatihan yang digunakan & 2 & 3 & 2 & 0 & 21 & $\mathrm{~B}$ \\
\hline 7 & $\begin{array}{l}\text { Bagaimana teknik penyajian materi jika dibandingkan } \\
\text { dengan metode ceramah }\end{array}$ & 2 & 3 & 2 & 0 & 21 & B \\
\hline 8 & Interaksi pelatih dengan peserta pelatihan & 2 & 3 & 2 & 0 & 21 & $\mathrm{~B}$ \\
\hline \multirow[t]{4}{*}{9} & Pemahaman peserta setelah mengikuti pelatihan ini & 2 & 4 & 1 & 0 & 22 & $\mathrm{BS}$ \\
\hline & Jumlah & 18 & 30 & 14 & 1 & 191 & \\
\hline & Jumlah Total & \multicolumn{4}{|c|}{63,0} & 21.2 & B \\
\hline & Persentase & 28.6 & 47.6 & 22.2 & 1.6 & & \\
\hline
\end{tabular}

Ket: K (kurang), C (cukup), BS (Baik Sekali), B (baik),

Dari hasil kuisioner yang telah diberikan kepada peserta pelatihan, Hasil kuesionernya diolah menggunakan uji skala Likert. Pada tabel 5 menunjukkan data dan hasil analisis penilaian peserta terhadap penyelenggara kegiatan. Pada penyelenggaraan kegiatan ada 4 pertanyaan yaitu tentang kepuasan pengelolaan dan ketepatan waktu, kesesuaian tema dan improvisasi terhadap teknik pelatihan. Hasil Uji menunjukkan penyelenggaraan kegiatan dikategorikan sangat sesuai dengan perolehan skor 22. Nilai 22 ini merupakan nilai minimal dari penentuan kategori sangat sesuai. Jika dilihat dari persentasenya $71.4 \%$ menyatakan penyelenggaraan kegiatan sesuai dan hanya $28.6 \%$ menyatakan sangat sesuai. Sisanya menyatakan $7.1 \%$ menyatakan kurang sesuai.

Pada tabel 6. Menunjukkan hasil penilaian peserta pelatihan terhadap kelengkapan materi, sikap, kemampuan, penyajian maupun interaksi pelatih, alat bantu pelatihan dan metode pelatihan. Skor yang diperoleh pada kuesioner penilaian pelatih adalah 21.2 sehingga bisa dikategorikan baik. Adapun persentase kepuasan personil terhadap pelatih $47.6 \%$ menyatakan baik, $28.6 \%$ menyatakan sangat baik, $22.2 \%$ menyatakan cukup dan sisanya menyatakan kurang. 


\section{KESIMPULAN}

Agar memiliki pemahaman yang komprehensif tentang SNI ISO/IEC 17025:2017, telah dilakukan pelatihan kepada kepada personel PT XYZ. Pelatihan ini menerapkan metode pembelajaran kooperatif JIGSAW. Berdasarkan hasil analisis uji t-test dan uji skala likert melalui pretest dan posttest, pelatihan metode JIGSAW ini berhasil meningkatkan pemahaman personel sebesar $35 \%$ dan juga menunjukkan penilaian peserta pelatihan terhadap pelatih adalah dalam kategori Baik dan penilaian peserta terhadap penyelenggaraan kegiatan adalah sangat sesuai. Sehingga dapat disimpulkan bahwa pelatihan interpretasi pemahaman personil terhadap SNI ISO/IEC 17025:2017 menggunakan metode JIGSAW efektif untuk diterapkan dibandingkan metode ceramah. Kedepannya, untuk melakukan pengujian efektivitas dan keberhasilan lebih lanjut, pelatihan SNI ISO/IEC 17025:2017 menggunakan metode JIGSAW ini akan dikomparasikan dengan metode lain dan diterapkan di lingkup perusahaan uji kalibrasi alat kesehatan dengan jumlah SDM yang lebih besar dan sudah memiliki setidaknya kesadaran dan pemahaman tentang standar.

\section{DAFTAR PUSTAKA}

[1] D. Nur Faridah, D. Erawan, K. Sutriah, A. Hadi, and F. Budiantari, Implementasi SNI ISO/IEC 17025:2017 - Persyaratan Umum Kompetensi Laboratorium Pengujian dan Laboratorium Kalibrasi. 2018.

[2] KEMENTERIAN KESEHATAN, "Peraturan Menteri Kesehatan Republik Indonesia Nomor 54 Tahun 2015 Tentang Pengujian Dan Kalibrasi Alat Kesehatan," Menteri Kesehat. Republik Indones. Peratur. Menteri Kesehat. Republik Indones., 2015.

[3] K. K. RI, Permenkes No. 26 tahun 2018 tentang Pelayanan Perizinan Berusaha Terintegrasi secara Elektronik Sektor Kesehatan. 2018.

[4] A. S. Nugroho, P. W. Wardaningsih, and M. Yono, "Pengaruh Tingkat Pengetahuan Tentang Kalibrasi Terhadap Perilaku Mengkalibrasikan Alat Sphygmomanometer Pada Bidan Praktek Mandiri Di Puskesmas Wilayah Kabupaten Demak," J. Ilmu dan Teknol. Kesehat., 2017, doi: 10.33666/jitk.v8i1.45.

[5] Standar Nasional Indonesia, "Persyaratan umum kompetensi laboratorium pengujian dan laboratorium kalibrasi, SNI ISO/IEC 17025:2008," Badan Stand. Nas., 2008.

[6] N. Khurotin and T. W. Afrianty, "Analisis Pelatihan dan Pengembangan Sumber Daya Manusia di PT Beon Intermedia Cabang Malang," J. Adm. Bisnis, 2018.

[7] S. Tambak, "Metode Ceramah: Konsep Dan Aplikasi Dalam Pembelajaran Pendidikan Agama Islam," J. Tarb., 2014.

[8] H. Maurin and S. I. Muhamadi, "Metode Ceramah Plus Diskusi dan Tugas Untuk Meningkatkan Aktivitas Belajar Siswa," al-Aulad J. Islam. Prim. Educ., 2018, doi: 10.15575/al-aulad.v1i2.3526.

[9] "Pengaruh Metode Pembelajaran Ceramah Plus dan Metode Drill terhadap Motivasi Belajar dan Hasil Belajar pada Kompentensi Dasar Efisiensi penggunaan Tempat Tidur Rumah Sakit," Pengaruh Metod. Pembelajaran Ceramah Plus dan Metod. Drill terhadap Motiv. Belajar dan Has. Belajar pada Kompentensi Dasar Efisiensi Pengguna. Tempat Tidur Rumah Sakit, 2017, doi: 10.15294/miki.v7i1.11134.

[10] R. Ranabumi, M. Rohmadi, and S. Subiyantoro, "Penggunaan Metode Ceramah Dalam Pembelajaran Menulis Teks Eksposisi Pada Siswa Kelas Vii-B Smp Negeri 5 Kediri,” Proc. Educ. Lang. Int. Conf., 2017.

[11] R. Ketut, "Implementasi Model Pembelajaran Kooperatif Tipe Jigsaw untuk Meningkatkan Sikap Demokrasi Peserta Diklat Prajabatan di Provinsi Bali," J. Wacana Kinerja Kaji. Prakt. ..., 2018.

[12] M. Ifa, "Penerapan model pembelajaran kooperatif tipe jigsaw untuk meningkatkan hasil belajar siswa kelas X SMK Negeri 3 Boyolangu pada standar kompetensi menerapkan keselamatan dan kesehatan kerja ( K3 )," J. Pendidik. Tek. Elektro, 2013.

[13] W. K. Wardani and S. Samidjo, "Upaya Meningkatkan Aktivitas Belajar Mata Pelajaran Sistem Rem Dengan Menggunakan Model Pembelajaran Kooperatif Tipe Jigsaw Siswa Kelas Xi Teknik Kendaraan Ringan Smk Tamansiswa Jetis Yogyakarta Tahun Pelajaran 2015/2016," TAMAN VOKASI, 2017, doi: 10.30738/jtvok.v5i1.1540. 